\title{
Maori Are Scum, Stupid, Lazy: Maori According to Google
}

The world has become more interconnected which has changed the way we communicate (Steinfeldt et al., 2010). As technology has continually developed allowing instant online publication, an increasing abundance of opinionated discourse has appeared on the worldwide web (Chelaru, Altingovde, Siersdorfer \& Nejdl, 2012). From blogs that disseminate political ideologies, to hair and makeup tutorials, the internet has become a medium that facilitates unfiltered instantaneous communication to a potentially global audience. While most users of internet services utilise the technology to engage in civilised dialogue, it does not require much effort to locate capricious behaviour in the anonymised online environment.

For example, online forums have been used to promulgate racist literature and imagery (Steinfeldt et al., 2010) which is demonstrated in the New Zealand context on multiple online forums whereby racist remarks against Maori and other nonPakeha ethnic groups are posted on a regular basis. The forums are hosted on servers located both in New Zealand and overseas. An observation of user data from such forums reveals that those responsible for the indecorous online attacks against Maori are perpetuated by the philistines of Pakeha society; those who indoctrinate the notion of 'Maori privilege' and cast blame on Maori for their own lack of success in the Pakeha world. This is evidenced by accessing other postings by the users, cross checking of pseudonyms 
and usernames with other web services and analysing the content on their social networking accounts, among other methods. This profusion of online putridity has impacted upon internet search engines by manipulating the predictive text capabilities that exist in many of the search engine interfaces. This paper highlights the issue surrounding racist suggestions within Google's Autocomplete function.

Internet search engines such as Google and Yahoo, are essentially searchable databases of websites and online content which are collated by web crawlers, a type of software, that systematically browse the worldwide web following hyperlinks from one page to another (Taylor, 2010). Search engines "represent the beating heart of the web" (Taylor, 2010, p. 16) and influence much of what information is viewed online by recommending websites to be visited. In online reality, search engines are the gateway to public information and control to a large degree what content will be viewed by users, and what content will be inaccessible. According to Azzopardi and Owens (2009), the order in which websites are recommended by search engines "dictate to a large extent, if not completely, what information is accessed during a user's online experience" (p. 1). Furthermore, search usage provides the search engine companies with valuable data which enables them to determine "who searches for what, along with several characteristics about each user (location, time, device, etc.)" (Mazieres \& Huron, 2013, p. 244). The world's most popular search engine is Google (Mazieres \& Huron, 2013) which receives 17 billion queries per month from users in the United States alone (Hannak et al., 2013).

As the internet is continually evolving with innovative features, search engines are also developing (M. L. Smith, 2013). A tool that Google has incorporated into their search engine interface is called Autocomplete. Autocomplete is essentially a mechanism that offers search suggestions to 
users as text is entered into the search box (Ward, Hahn \& Feist, 2012). Other applications also utilise this technology due to the convenience of use, such as command shells, mobile applications, desktop computer search and software development environments (Xiao, 2013). Google (2014) explains Autocomplete on their support page:

As you type within the search box on Google, Autocomplete helps you find information quickly by displaying searches that might be similar to the one you're typing. For example, as you start to type "new york", you may be able to pick searches for other New York-related search queries (para. $1)$.

\begin{tabular}{|l|l|}
\hline new york| \\
\hline new york times \\
new york \\
new york and company \\
new yorker \\
\hline Press Enter to search. \\
\hline
\end{tabular}

\section{Figure 1: Autocomplete (Google, 2014)}

The Autocomplete tool has obvious advantages for users which Google (2014) emphasises such as allowing the user to type less, finding information quicker, and discovering other relevant information, among others. However, the crux of this paper is to present how Maori are portrayed in Google's Autocomplete feature. Firstly, it is important to note that according to Google (2014) "search queries that you see as part of Autocomplete are a reflection of the search activity of users and the content of web pages indexed by Google" (para. 3). As such the following captures are representative at the time of authoring this paper. The web browser used for this research was Internet Explorer and the searches were 
conducted in New Zealand. However, associates in overseas countries also undertook the same search queries which concluded identical Autocomplete results as described below.

Several keywords relating to Maori were entered into the Google search engine. Below are the search queries and the Google Autocomplete suggestions.

1. The text "maori are" followed by the space key were inputted into Google search and the following suggestions were returned:
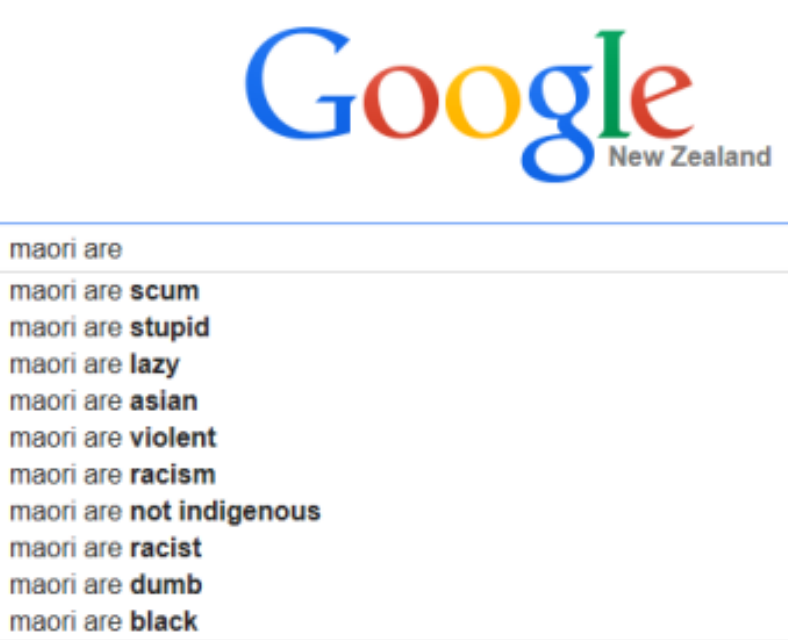
2. The text "why are maori" followed by the space key were inputted into Google search and the following suggestions were returned:

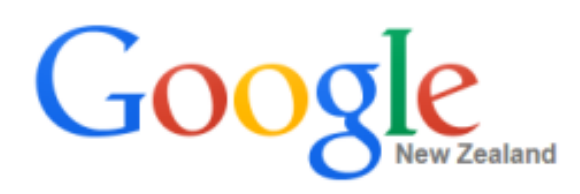

why are maori|

why are maori obese

why are maoris so poor

why are maoris so big

why are maoris so lazy

why are maoris so violent

why are maoris so fat

why are maoris so dumb

why are maoris so racist

why are maoris so ugly

why are maoris stupid

Other variations of suggestions relating to "Maori" in Google Autocomplete will most likely incur similar outcomes. As mentioned above, Google (2014) stipulated that the results of Autocomplete are driven by the search activity of their users and indexed websites. If that statement is to be taken as fact regarding the Autocomplete taxonomy, it questions the morality and the mental wellbeing of a sector of society who input drivel into the Google search engine and publish or post hateful anti-Maori sentiment online.

The stereotyping and misrepresentation of Maori is not a recent phenomenon as research since the 1950s has reliably determined that Pakeha hold unfavourable views of Maori, for example "Maori have been viewed as trouble-makers, lazy, unintelligent, dirty, aggressive, easygoing and friendly, 
whereas Pakeha have been regarded as successful, hardworking, intelligent and self-centred" (Holmes, Murachver $\&$ Bayard, 2001, p. 79). As expressing overt racist views have become socially unacceptable, other strategies to convey racism has permeated. For example, the supercilious discursive pattern that usually begins with "I'm not racist but..." or "my best friend is brown" suggests that what follows cannot be racist but usually is (M. S. Smith, 2008). While van Dijk (1992) posited that another artifice to camouflage racist connotations is to redefine racism altogether and also to use the "we are not the racists, they are the real racists" line, which is seen repetitively in the comments sections of New Zealand's online news services and similarly the popular blogs aligned to the right of the political spectrum. The development of the internet has allowed racism to transition into the online environment where racist rhetoric can now be overtly expressed incognito rather than using subtle and indirect forms of racist discourse. The racist search queries and online postings have influenced Google's Autocomplete which has resulted in the above suggestions when searching for Maori. Some other ethnic groups are experiencing similar outcomes, while other groups such as Pakeha, are not victims of racism in Google's Autocomplete.

A comparison search of some ethnicities was undertaken in Google search to determine if Autocomplete would offer similar suggestions. For example, Pakeha, Caucasians, Whites, White people, Jews, African Americans, and even explicit derogatory terms such as Nigger, Niggers etc. were typed into Google search. All of the aforementioned did not generate any racist suggestions when entered into Google search. In fact, most received no suggestions whatsoever. However, Australian Aboriginals (under the search term "Aborigines" and "Abos") and some Pacific Island ethnic groups suffered similar outcomes to Maori. While the author did not 
input every single ethnic group into Google to query the Autocomplete suggestions; it is manifestly evident that racial hatred towards Maori is perpetuated in Google's Autocomplete predictive text function. What further aggravates the matter is that Google (2014) have stated that Autocomplete cannot be disabled within a user's browser; although Google has blacklisted certain words within Autocomplete queries (M. L. Smith, 2013) which may elucidate why some ethnic groups are not subject to the same attacks as Maori.

It is fair to conclude that the idiosyncratic nature of Google's Autocomplete is currently facilitating racism against Maori by permitting racist suggestions as demonstrated above, which is a direct result of racism in the online environment. The same situation exists for our Australian Indigenous counterparts and some Pacific Island groups. This matter needs to be addressed and the appropriate steps taken by Google. 


\section{References}

Azzopardi, L., \& Owens, C. (2009). Search engine predilection towards news media providers. Retrieved from http://www.dcs.gla.ac.uk/ leif/papers/sigir2009-search-enginebias.pdf

Chelaru, S., Altingovde, I. S., Siersdorfer, S., \& Nejdl, W. (2012). Analyzing, detecting and exploiting sentiment in web queries. Retrieved

from http://www.13s.de/ siersdorfer/sources/2013/tweb13sentiment-queries.pdf

Google. (2014). Autocomplete. Retrieved from https://support.google.com/websearch/answer/106230?hl=en

Hannak, A., Sapiezynski, P., Kakhki, A., Krishnamurthy, B., Lazer, D., Mislove, A., \& Wilson, C. (2013). Measuring personalization of web search. Proceedings of the International World Wide Web Conference, 22, 527-538. Retrieved from http://www2013.org/proceedings/p527.pdf

Holmes, K., Murachver, T., \& Bayard, D. (2001). Accent, appearance, and ethnic stereotypes in New Zealand. New Zealand Journal of Psychology, 30(2), 79-86.

Mazieres, A., \& Huron, S. (2013). Toward Google borders. Proceedings of the 2013 ACM Web Science WebSci, 13, 244-247. doi:10.1145/2464464.2464525

Smith, M. L. (2013). Search engine liability for autocomplete defamation: Combating the power of suggestion. Journal of Law, Technology \& Policy, 313, 314-336. Retrieved from http://illinoisjltp.com/journal/wpcontent/uploads/2013/12/Smith.pdf

Smith, M. S. (2007). Editorial: Racism and motivated ignorance. The Ardent: Anti-Racism \& Decolonization Review, 1(1). Retrieved from http://www.artsrn.ualberta.ca/aadr/Documents/TheArdentRevie w1-1_final2\%5B1\%5D.pdf

Steinfeldt, J. A., Foltz, B. D., Kaladow, J. K., Carlson, T. N., Pagano, L. A., \& Benton, L. (2010). Racism in the electronic age: Role of online forums in expressing racial attitudes about American Indians. Cultural Diversity \& Ethnic Minority Psychology, 16(3), 362-371. doi:10.1037/a0018692 
Taylor, G. (2010). What makes Google tick? Economic Review, 28(2), 16-19.

van Dijk, T. A. (1992). Discourse and the denial of racism. Discourse \& Society, 3, 87-118.

Ward, D., Hahn, J. \& Feist, K. (2012). Autocomplete as a research tool: A study on providing research suggestions. Information Technology and Libraries, 31(4), 6-19. Retrieved from http://ejournals.bc.edu/ojs/index.php/ital/article/view/1930

Xiao, C., Qin, J., Wang, W., Ishikawa, Y., Tsuda, K., \& Sadakane, K. (2013). Efficient error-tolerant query autocompletion. Retrieved from

http://www.cse.unsw.edu.au/ jqin/papers/fastss_vldb2013.pdf 